\title{
Erratum to: Enhancement of silicon nanowire opto-electric properties by combining acid vapor etching and lithium pore- filling
}

\author{
Chohdi Amri $^{1,3} \cdot$ Rachid Ouertani $^{2} \cdot$ Abderrahmane Hamdi $^{1,3} \cdot$ Hatem Ezzaouia $^{1}$
}

Published online: 13 July 2017

(C) Springer Science+Business Media, LLC 2017

\section{Erratum to: J Mater Sci: Mater Electron}

DOI 10.1007/s10854-017-7181-2

The original version of this article unfortunately contained mistakes in the author name and the affiliation.

1. The third author's name should be read as "Abderrahmane Hamdi" instead of "Abderrahamn Hamdi"

2. The affiliation of the first and third author should read as: Chohdi Amri 1,3* and Abderrahmane Hamdi 1,3

The online version of the original article can be found under doi:10.1007/s10854-017-7181-2.

Chohdi Amri

Chohdiamri@gmail.com

1 Laboratory of Semi-conductors, Nano-structures and Advanced Technologies, Research and Technology Centre of Energy, Borj-Cedria Science and Technology Park, BP 95, 2050 Hammam-Lif, Tunisia

2 Photovoltaic Laboratory, Research and Technology Centre of Energy, Borj-Cedria Science and Technology Park, BP 95, 2050 Hammam-Lif, Tunisia

3 Faculty of science of Bizerte, University of Carthage, 7021 Zarzouna, Tunisia 